\title{
The influence of executive function challenges on the behavioural adaptation of one learner with autism spectrum disorder
}

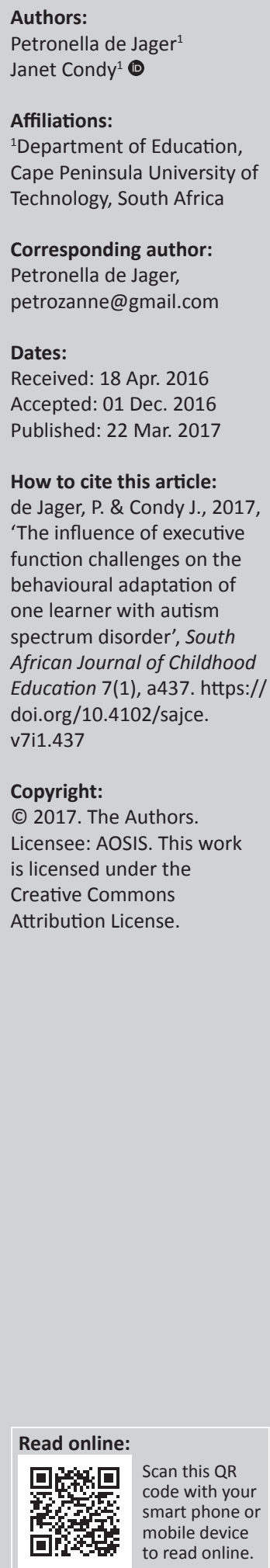

In South Africa, many learners with autism spectrum disorder (ASD) attend mainstream and private schools. This study explores the influence of executive function (EF) challenges experienced by one learner with ASD on his behavioural adaptation in an inclusive school environment. An interpretive case study approach was followed to help understand one unique ASD learner and explain the complexity of the behavioural adaptation challenges that he was experiencing. Observations and an interview were used as data collection methods. During data analysis, themes were identified within each section of the transcript. The processes of coding and categorising were employed to find connections and similarities between all the data collected. The results indicate that Learner T experienced EF challenges. Without acquiring and implementing appropriate EF skills, he found it difficult to exhibit appropriate social behaviour in the inclusive learning environment. The study attempts to debunk misconceptions people may have regarding the behavioural adaptability of ASD learners in an inclusive school environment.

\section{Introduction}

To keep up with international trends, South Africa has embraced the establishment of an inclusive educational system (South Africa, Department of Basic Education 2014; South Africa, National Department of Education 2001, 2002). The White Paper 6 (2001) policy on Special Needs Education in South Africa has continued to provide an important framework to guarantee the right to quality education for children with disabilities (United Nations Children's Emergency Fund [UNICEF] 2012:17). White Paper 6 (2001:17) states that inclusion is about recognising and respecting the differences among learners while building on their similarities. It is about support for both learners and educators. The emphasis is on development and teaching strategies with an adaptive support system that will benefit all learners in need. Unfortunately, although sound in theory, the White Paper 6 policy is difficult to implement in schools (Donohue \& Bornman 2014; Engelbrecht et al. 2003; South Africa, Department of Basic Education 2015; South Africa, National Department of Education 2008). The SIAS $(2008,2014)$ documents were developed by the South African Department of Basic Education in an attempt to bridge the theory and practice gap. In all these documents, autism spectrum disorder (ASD) learners are included in the inclusive mainstream South African educational system.

The aim of this study was to conduct an in-depth experiment of how executive function (EF) challenges can influence the behavioural adaptation of one 9-year-old ASD learner. The reason why this study focused on only EF challenges was that, according to Best and Miller (2010), despite large literature on EF in children it mainly focuses on very young children before the age of five. As Hughes and Graham (2002) mentioned that investigation is needed to establish whether contrasts in EF help explain differences in the form and severity of behavioural symptoms, the research investigated the influence EF had on the behavioural adaptation of a learner with ASD.

According to De Luca and Leventer (2008), EF development corresponds to the neurophysiological developments of the growing brain, and as the processing capacity of the frontal lobes and other interconnected regions increases, the core EF will thus emerge. As EF 'comprises of a set of cognitive control processes, which regulates lower level processes (e.g., perception, motor responses), it thereby enables self-regulation and self-directed behaviour towards goals' (Miyake \& Friedman 2012:8). The lower level of processes are needed for cognitive control of behaviour by selecting and successfully monitoring behaviours that facilitate the attainment of chosen goals. They include attentional control, inhibitory control, working memory, cognitive 
flexibility, reasoning and problem-solving. EF skills gradually develop and change across the lifespan of an individual (Diamond 2013; Malenka, Nestler \& Hyman 2009).

While evaluating the theory on executive dysfunction in autism, Hill (2004) argued that although many children with autism have difficulties with EF, it cannot be considered a defining feature of autism as not all ASD children have difficulties with EF. As a result, autism treatment has largely excluded assessment and treatment of EF and focused instead on the social communication of all individuals on the ASD spectrum.

Wertz (2012:1) stated that 'The tendency to ignore EF in autism has had significant implications for those individuals on the ASD spectrum who have difficulties with EF (estimated to be as high as $80 \%)^{\prime}$. He argued that these individuals do not progress well with social and communication issues without also addressing their EF problems.

In 2008 and 2009, the researcher conducted a case study on two Grade R learners experiencing Asperger's syndrome as well as sensory processing difficulties (De Jager \& Condy 2011). This prompted her to continue her study of Asperger's syndrome learners, especially those entering the Intermediate Phase of their school career (10-12 year-olds). While exploring the recent literature, she discovered that a new Diagnostic and Statistical Manual (5th edition, DSM-V) had been published (American Psychiatric Association 2013). It was interesting to note that subsequently the criteria for Asperger's syndrome had undergone changes. The new DSM-V diagnoses all autistic individuals with ASD. Within this classification, ASD learners are grouped according to the level of support they need. The three levels comprise 'requiring very substantial support', 'requiring substantial support' and 'requiring

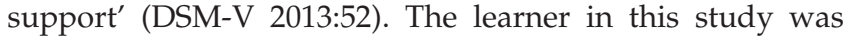
categorised as 'requiring support'.

In the DSM-V (2013), there are two criteria describing ASD. Criterion A focuses on social communication and social interaction, and Criterion B focuses on restricted patterns of behaviour, interests or activities (American Psychiatric Association 2013:50). This study is confined to the social interactional behaviours of ASD, that is, Criterion A. Within this criterion, there are three subcategories of deficit that were used by the researcher to inductively analyse the data.

Criterion A (DSM-V 2013:50) is described as: 'Persistent deficits in social communication and social interaction across multiple contexts, as manifested by the following, currently or by history (examples are illustrative, not exhaustive)'. The three subcategories that fall under Criterion A include:

1. deficits in social-emotional reciprocity, ranging, for example, from abnormal social approach and failure of normal back-and-forth conversation to reduced sharing of interests, emotions, or affect to failure to initiate or respond to social interactions

2. deficits in non-verbal communicative behaviours used for social interaction, ranging, for example, from poorly integrated verbal and non-verbal communication to abnormalities in eye contact and body language or deficits in understanding and use of gestures to a total lack of facial expressions and non-verbal communication

3. deficits in developing, maintaining and understanding relationships, ranging, for example, from difficulties adjusting behaviour to suit various social contexts to difficulties in sharing imaginative play or in making friends to absence of interest in peers.

As social communication and social interaction are regarded as inseparable, they can be more accurately considered as a single set of behaviours with contextual and environmental specificities (Herold 2013). DSM-V Criterion A-3 makes mention of 'difficulties adjusting behaviour'. According to Weiten, Dunn and Hammer (2011), 'adjustment in behaviour' is a psychological process through which, for instance, a learner will manage or cope with the demands of his or her school environment and experiences associated within this environment.

As this study focuses on the influence EF can have on the behaviour of an ASD learner, the researcher preferred to use the phrase 'adaptation of behaviour'. The American Association on Intellectual and Developmental Disabilities (2013) defines behavioural adaptation as a collection of conceptual, social and practical skills that are learned and performed by people in their everyday lives. Conceptual skills are needed to understand language, number concepts and self-direction. Social skills are important for interpersonal and social responsibility, problem solving and the ability to follow rules. Practical skills are required for activities in daily living, including personal care, safety and following routines.

The following section describes in more detail the five subdomains of EF that may influence behavioural adaptation. These include response inhibition, emotional control, task initiation, goal-directed persistence and sustained attention, and flexibility of thinking. Examples are given to illustrate how the lack of these EF skills may influence behavioural adaptation in a classroom situation.

\section{Executive function}

According to Dawson and Guare (2012), the term EF emanated from the discourse of neuroscience and refers to the brainbased skills that are required for humans to perform a task or interact appropriately. They stated that there are two dimensions of EF skills, involving cognition and behaviour. This study focusses on the 'behavioural adaptation' which includes the EF subdomains of response inhibition, emotional control, task initiation, goal-directed persistence and sustained attention, and flexibility of thinking.

An ongoing study at the Centre on the Developing Child at Harvard University (2011:3; working paper 11) stated that:

the scientific evidence on the development and consequences of EF in the early years of life conveys three important messages. 
First, EF skills are crucial building blocks for the early development of both cognitive and social capacities. Second, both normative differences in the nature and pace of individual developmental trajectories and the impacts of significant adversity will affect how the development of EF evolve for any given child. Third, several interventions focused on supporting the development of specific EF skills have demonstrated at least short-term effectiveness.

Birtwell, Willoughby and Nowinski (2016) concurred with DSM-V that in addition to communication and social challenges, an ASD learner can encounter behavioural challenges. Greenstone (2011) explained that although educators may be aware of EF skills, they may be overlooking their important implications in the foundation of both academic and behaviour problems. The importance of being aware of the influence of the five behavioural EF skills and how they might influence an ASD learner's behaviour during social communication and interaction will be discussed in the following section.

\section{Response inhibition}

Response inhibition is the ability to think before you act. This skill is important in resisting the urge to say or do something before you have had a change to evaluate the situation (Greenstone 2011). While all EF skills are important, when it comes to young school-going children, it is important for them to have the capacity to manage their response inhibition so that they do not routinely engage in impulsive and risky behaviour (Guare, Dawson \& Gaure 2013).

Richardson (2008) points out that ASD individuals often lack the ability to suppress or ignore irrelevant or interfering stimuli or information that transpires during communication and social interaction. The young 9-year-old ASD learner in this study was chosen because, as Attwood (2007) states, in the early years one of the main signs of impaired EF is difficulties in inhibiting responses (i.e. being impulsive responses).

Yigal et al. (2010) agreed that individuals on the ASD spectrum consistently display deficient response inhibition, which may exhibit itself through context-inappropriate behaviour. They would show emotions that were inconsistent with normative appraisal of the context (Locke et al. 2009).

In a classroom situation, an ASD learner may show a lack of response inhibition by not being able to suppress irrelevant or interfering information and impulses. Not being able to control his or her response inhibition impulses can result in finding it difficult to resist the urge to say or do something before thinking of the consequences. According to Dawson and Gaure (2009), experiencing challenges with response inhibition can influence an ASD learner's behavioural adaptation in numerous ways. Examples include not being able to walk away from confrontation or provocation by a peer, not being able to resist a fun activity despite a change of plans and not being able to resist saying hurtful things within a group situation.

\section{Emotional control}

Greenstone (2011) states that emotional control is a vital EF skill to manage emotions to achieve goals, complete tasks, and control and direct behaviour. When learners lack the skill of emotional control in the classroom, they may display 'sudden/frequent mood changes, be emotionally reactive and show periods of excessive emotional upsets' (Greenstone 2011:105).

Controlling one's emotions is an important factor in everyday functioning (Gross 2007). Gross agreed that to function in everyday situations one needs to control one's emotions through regulating one's voice and body in order to achieve goals and complete tasks. According to Gross (2007), failing to adequately control one's emotions can have serious consequences for one's well-being and social relationships.

Samson et al. (2014) posit that emotional control is not a formal criterion for the diagnosis of ASD. Yet clinicians and parents have long noted the importance of emotional control in respect of tantrums and anger outbursts on the part of ASD children. Attwood (2007) states that children with ASD clearly have problems with understanding emotions within themselves and others, and with expressing emotions at an appropriate level for the situation. Greenstone (2011) argued that a learner who lacks the EF skill to control his or her emotions will be unable to modify his or her behaviour and act in a socially acceptable manner. Dawson and Gaure (2009:207) point out that a learner who lacks emotional control skills will find it difficult to tolerate criticism from his or her teacher. He or she will become overly upset when dealing with perceived 'unfairness' and will also find it difficult to act with restraint in response to teasing or disagreements.

\section{Task initiation}

Richardson (2008) described task initiation as knowing how to get started, and how to sustain the effort level needed to complete a task. It is the ability to begin projects without undue procrastination in an efficient and timely manner (Dawson \& Gaure 2009:16). Thus, when task initiation becomes a challenge, the timeous start and efficient and correct completion of the goal or task at hand is at risk.

Dawson and Gaure (2009:222) argued that task initiation does not apply to tasks we want to do but only to those we find unpleasant, aversive or tedious - 'one we have to make ourselves do'. In a classroom situation, Attwood (2007) mentioned that an ASD learner is often willing to start a task, but will use his or her own time frame and strategy that often do not comply with the instructions given by the teacher.

Greenstone (2011) argued that often the reason for not starting a task timelessly is that the learner does not show understanding of where to start, or the steps to follow to complete the task. Often when an ASD learner experiences a task initiation challenge, it may be misinterpreted as a lack of 
cooperation, a lack of motivation or reluctance to respond or following instructions or rules (Wertz 2012).

\section{Goal-directed persistence and sustained attention}

The ability to sustain attention has been used adjacent to goal-directed persistence because, as Dawson and Gaure (2012:11) argue, goal-directed persistence includes the skill of sustained attention that enables an individual to keep paying attention so as to complete the set task or achieve the set goal. They (2009:265) define goal-directed persistence as 'setting a goal and working towards it without being side-tracked by competing interests'. Sustained attention is the 'capacity to keep paying attention to a goal or task despite distractions, fatigue or boredom' (Dawson \& Gaure 2009:214).

According to Davide-Rivera (2015), it is often difficult for those individuals on the ASD spectrum to work towards goals. They have trouble deciding what to do next, which often results in their losing focus, no longer paying attention and thus losing interest in completing a task. Attwood (2007:256) mentions that an ASD learner can be easily distracted. When working towards completing a task, he or she will appear to have a 'one track mind' and a fear of failure.

Herbert and Weintraub (2012) argue that in a classroom situation, not persevering and paying attention to complete a task is often triggered by social distraction (such as misunderstanding by peers), sensory stimulation and overload or competing interests. Refocusing on his or her own interests may be the result of the ASD learner's misunderstanding of the teacher's instructions or not finding the task engaging or interesting enough (Herbert \& Weintraub 2012).

\section{Flexibility of thinking}

According to Kashdan and Rottenberg (2010:865), flexibility of thinking 'measure[s] how an individual adapts to fluctuating situational demands, reconfigures mental resources and shifts perspectives'. They argue that flexibility of thinking is needed to balance competing desires, needs and life domains. Flexibility of thinking enables individuals to generate new ways of looking at a problem in order to accept change and to adapt to the unexpected.

Cannon et al. (2011) stress that learners with ASD often display flexibility of thinking challenges. Elliot (2013) furthers this discussion by stating that this is an important skill for academics, particularly when learning complex material in which making mistakes may be the best way to solve a problem. He argues that the skill of flexibility of thinking helps an ASD learner focus and adapt to new situations, improvise and shift strategies to meet different types of challenges.

\section{Research approach}

This study is grounded in a qualitative case study conducted within an interpretative research paradigm. Yin (2003:18) defines a case study research as comprising an all-encompassing method covering the logic design, data collection techniques and specific approaches to data analysis. It is a preferred strategy when 'how' and 'why' questions are posed, the researcher has little or no control over events and the focus is on a contemporary phenomenon within some real-life context. This inquiry was followed to help understand one unique ASD learner and explain the complexity of the behavioural adaptation challenges that he was experiencing in his classroom. An interpretive research approach is 'an approach that focusses on examining how individuals make meaning of their life experiences' (Pietkiewiz \& Smith 2014:7). It is informed by the idea that everyone is unique and should be studied as such. This approach involves a combination of psychological, interpretative and ideological components (Gill 2014). Together these afford an in-depth understanding that incorporates attention to the participant's beliefs and subjective experiences, feelings and values (Nichols 2011).

This study focused on ascertaining the influences EF challenges may have on the behavioural adaptation of a learner with ASDs. It is therefore subjective to the observation obtained through the personal perspective and interpretation of the information gathered from observed behavioural responses of the ASD learner and the interview conducted with the Grade 3 teacher.

Finding a learner who can fulfil all the requirements needed to qualify for this study was difficult. The researcher found that the learners she identified, the schools and parents were unwilling to be involved in the study. Therefore, this learner was purposively 'hand-picked' on the basis that he was clinically diagnosed with ASD by a registered educational psychologist. At the time of data collection, he was a 9-yearold learner in Grade 3 in a private school in the Cape Peninsula. According to Cohen, Manion and Morrison (2008:114), in purposive sampling:

researchers' 'hand-pick' the cases to be included in the sample on the basis of their judgement of their typicality. In this way they build up a sample that is satisfactory to their specific needs.

By employing observations and an interview for data collection, the researcher was able to study Learner $T^{\prime}$ s behaviour from more than one standpoint (Henning Van Rensburg \& Smit 2007). The focus was on his behaviour, but the researcher tried to interpret the reasons behind it - to establish the influences of EF challenges experienced by an ASD learner on his behavioural adaptation in an inclusive school environment. As the number of occurrences of certain phenomenon mounted, using both observations and an interview as data collection instruments enabled the researcher to triangulate the information. It was hoped that this would heighten the dependability and trustworthiness of the interpretation of the data collected (Zohrabi 2013).

The researcher put aside five school days (between 08:30 and 14:30) for continuous observations during August-September 2013. The researcher decided to conduct the observations only in the third term as this would have allowed Learner L 
time to adapt to his Grade 3 school environment. His teacher would then also have had time to get to know him as a unique individual and help him acquire and manage, for example, appropriate social adaption skills.

During this time, Learner $\mathrm{T}$ engaged with different learning areas or subjects (Home Language, First Additional Language, Mathematics, Social and Natural Sciences, and Life Skills), while interacting with Teacher SM and other learners in the classroom. Learner $\mathrm{T}$ had additional periods of Computer Work, Physical Education, Library and Art, when he was required to leave his classroom environment.

During the observation period, minute-to-minute examples of behavioural adaptation challenges experienced by Learner $\mathrm{T}$ were noted on a preplanned observation schedule. The responses of Teacher SM to these behavioural challenges were included and correlated. This meant that the researcher could build up information from what she had observed and learnt from Learner T and Teacher SM, thus allowing space for both their 'voices' (Henning et al. 2007:83). By not only gathering information but also observing Learner T's interacting in his environment the researcher could experience the unique way in which the learner experienced life situations differently from his peers.

After the five observations, an interview was arranged with Teacher SM. The interview was tape-recorded to ensure descriptive validity (Isaac 2015). By reviewing and confirming the tape-recorded data against the notes taken during the interview, the validity, accuracy and clarity of the information was ensured, and it also helped determine how consistent the participant was in her provision of information.

The interview questions were fit for purpose, designed with the research question in mind. The semi-structured interview was conducted after-hours in Teacher SM's classroom. This style of interviewing allowed for more flexibility and created space for the researcher to pursue lines of inquiry stimulated by the interview (Rule \& John 2011). As Teacher SM was not formally trained in teaching ASD learners, probing questions were added where necessary. These probing questions assisted in helping her respond more fully and contributed more relevant information to the research results.

The researcher used standard procedures to organise, date and code the data from the observations and the one interview. This assisted her in establishing links between the various data collected (Henning et al. 2007). Once she had identified the themes within each section of the transcript, she looked for possible connections between them. The main theme comprised the identified 'EF challenges'. These five challenges included response inhibition, emotional control, task initiation, goal-directed persistence and sustained attention, and flexibility of thinking. The subtheme which was the 'behavioural adaptation challenges' juxtaposed all five themes. The next stage involved a more analytical or ordering process, as the researcher made sense of the connection between the main theme and subthemes as they emerged. The main five themes were categorised using grouping and colour-coding procedures. Every EF challenge was given a specific colour code, which included 'green' for response inhibition, 'blue' for emotional control, 'yellow' for task initiation, 'red' for goal-directed persistence and sustained attention, and 'purple' for flexibility of thinking challenges. The 'behavioural adaptation challenges' were individually identified and linked according to these EF challenges and colour-coded accordingly.

A tabular form was designed that included the EF challenge and its definition, the environment that the observation transpired in, the linked behavioural adaptation challenge and the response of the teacher to the behaviours.

So as not to fall prey to bias, the researcher made notes regarding the environment and external elements that may have had an impact on the research findings. Continuous writing incidents while observing Learner T were done while occurrences took place. As the themes emerged, the researcher linked the support-related data of the interview with Teacher SM and related research with the observation data. All these standard procedures helped to ensure that the data collected rendered a 'thick description' of all the occurrences taking place (Henning et al. 2007:85).

\section{Ethical considerations}

The researcher received written consent letters from Learner $\mathrm{T}^{\prime}$ 's parents. A written assurance was given that the names of the school and the participants would remain anonymous and confidential. The school is identified as School P, the learner in the study as Learner $\mathrm{T}$ and the teacher as Teacher $\mathrm{SM}$. In addition, the researcher received ethical permission from the Cape Peninsula University of Technology to conduct this study.

\section{Results}

In this section, the findings of the observations and the interview will be discussed. The five EF challenges experienced by Learner $\mathrm{T}$ and the behavioural adaptation challenges will be presented.

\section{Response inhibition challenge}

In an English literacy lesson, Teacher SM mentioned that they were going to practice words starting with the sound ' $f$ ' in cursive writing. Learner $T$ responded impulsively by saying: 'Oh! We are going to do the 'f...' word today.' This caused some of the peers to burst out laughing, which disrupted the focus and concentration of the whole class. Teacher SM ignored his outburst and after she got the class to refocus, she mentioned words starting with ' $\mathrm{f}$ ' such as 'fruit', 'friends', etc. She asked the class to contribute words as well.

Kana et al. (2007) confirm that the social inability to inhibit context-inappropriate behaviour is typical of autism. As Learner $\mathrm{T}$ could not resist the urge to shout out the verbal 
response that was inappropriate in timing and to the circumstance, he displayed response inhibition. By ignoring his outburst, Teacher SM tried to minimise the impact his verbal response had on the flow of the lesson. During the interview, Teacher SM agreed that Learner T would often verbally respond by saying exactly what he thought without considering the consequences of his words. Dawson and Guare (2009) explain that response inhibition is an important EF skill that helps with the capacity to think before acting. This capability to resist the urge to say something allows the child the time to evaluate a situation and how his or her behaviour may impact it.

\section{Emotional control challenge}

During an oral presentation by a peer on 'Space', Learner T got upset because he felt that the peer did not give the correct information on the topic 'Space'. He responded by calling the learner offensive names and calling him an '... outright liar ...'. Teacher SM asked him to leave the room to calm down and that she would speak to him after class about his behaviour. Learner T's response to leaving the classroom was by shouting out '... but I can prove to you he is lying'.

Learner $\mathrm{T}$ lacked emotional control when he showed his frustration and disappointment by verbally lashing out at his peer and Teacher SM in a socially unacceptable manner. In the interview, Teacher SM confirmed that Learner $\mathrm{T}$ did not recognise that others were allowed to have ideas and feelings on issues that were different from his. He would get upset if others did not 'recognise his point of view, or frame of reference'. This often led to Learner T displaying an inappropriate emotional response. Attwood (2007:130) confirms that a learner with ASD tends to 'lash out' emotionally when he or she feels overwhelmed by too much detail, or is overcome by feelings of being misunderstood. According to Dawson and Guare (2009), emotional control is an important EF skill needed to control unpleasant feelings, such as anxiety, frustration and disappointments, to achieve goals, complete tasks or control and direct behaviour.

\section{Task initiation challenge}

During an addition and subtraction Mathematics lesson, it took Learner $\mathrm{T}$ a while to put down a toy gun that he had made out of Lego and start working on his maths. He only started working after Teacher SM asked a few times. Learner $\mathrm{T}$ insisted he was only going to write down the answers. Learner T responds:

'I have done all this adding in my head. I don't need to show you if I know the answer is correct.'

\section{Teacher SM explains:}

'When you do maths in the higher grades you get marks for showing the method and how you got to the answer.'

Learner T responds:

'Yes, but you know that I know the answer. It's boring.'
Teacher SM showed him an example of the method of how to get to the answer. Meanwhile, Learner T kept rocking back and forth showing his frustration.

Teacher SM explains:

'I know you know the answer mentally, but now show me on paper how you arrived at your answer.'

Knott and Dunlop (2007) confirm that a learner with ASD often delays starting a task, just as he or she would find it difficult to understand a different point of view, or recognise an alternative course of action. This results in the learner avoiding starting an activity in a timeless fashion and completing it as per instruction.

Learner T only started his activity after he was prompted by Teacher SM a few times. Once he started, he insisted on only writing down the answers to the sums. He refused to show evidence of how he had arrived at the answer. He insisted that his answers were correct as he had worked them out mentally. Even when shown what was expected of him, he struggled to grasp the meaning behind the maths lesson. In the interview, Teacher SM stated that Learner T would often only start a task after he had been prompted by her. Frequently during a discussion or when assigned a task, he would focus on one detail of the task and then become unable to see the whole picture or main outcome.

According to Ylvisaker, Hibbard and Feeney (2006), initiating, or starting an activity or thought process, is typically included in lists of functions that compromise a person's executive or self-regulatory system. If a person has initiation impairment, it may result in the need for frequent initiation cues from others.

\section{Goal-directed persistence and sustained attention challenges}

During a Social Science lesson on 'Families and Homes', Learner $\mathrm{T}$ made inappropriate verbal and non-verbal communication by making grunting noises to cut out the construction noises from outside. He sat and 'mimicked' all the sounds around him while he was working. This caused him to lose interest in his work, which resulted in him turning around and poking his peers with a pencil for attention. He continued to sit and played games with a Lego gun that he had made. He interrupted his peers sitting around him by making 'shooting' noises. Teacher SM asked him three times to focus on his own work and not disturb his peers.

Learner T responded:

'... it's anyway too noisy outside to do anything that requires thinking.'

Teacher SM stepped outside and asked the construction workers if they could be more considerate and keep the noise to a minimum. She closed the door behind her. 
Learner T could not persevere with the task at hand as the construction noise and his an obsession with guns prevented him from staying focused and completing his work on the home and family task.

In the interview, Teacher SM confirmed that Learner T would show his discomfort when he experiences sensory overload, for example, from external noises. He would then lose focus and resort to inappropriate behaviour by making grunting noises or disturbing peers. She said that his fixation on the theme of 'army and guns' was having an impact on his concentration and focus in class.

Dawson and Guare (2010) state that having the capacity to have a goal, and follow through to the completion of that goal, can only be achieved if one is not put off or distracted by competing interests. DSM-V (2013) has identified and included inappropriate sensory reactions as one of the diagnostic criteria for ASD. This challenge of inappropriate sensory reactions can prevent an ASD learner working towards a goal if competing and distracting interests deter his or her attention (Dawson \& Gaure 2010).

\section{Flexibility of thinking challenge}

During a Life Skills lesson, Learner $\mathrm{T}$ found it difficult to adjust to a change of conditions and consequently communicated in a socially unacceptable way during the showing of a movie. It rained during a Physical Education lesson, so Teacher SM allowed the class to watch a movie.

\section{Learner T commented:}

$$
\begin{aligned}
& \text { '... I've seen this movie a thousand times. This is boring and } \\
& \text { unfair and it's not raining anymore...'. }
\end{aligned}
$$

Learner $\mathrm{T}$ kept chatting to his other peers without making eye contact. He could not sit still and kept giving facts about what was going to happen in the movie and why. His peers complained to Teacher SM that he was spoiling the movie for them. Learner $\mathrm{T}$ continued giving his own views on submarines that featured in the movie. Teacher SM asked him to stop talking.

Learner $\mathrm{T}$ responded:

'... but I am not telling them about the movie, just about cool submariners...'

This resulted in some of his peers moving away from him and the rest of them ignored him completely.

Learner T's reluctance to adapt to change was observed when the class had to move to a different environment that was not part of their normal daily routine. He reacted to the change of venue and routine by moving about, talking and volunteering information so as to pre-empt the story in the movie. He could not understand that his peers did not want him to communicate with them and were not interested in his views on submarines. His inability to accept change and be flexible in his thinking caused him to fail to adapt and respond in a socially inappropriate way.
During the interview, Teacher SM acknowledged that Learner $\mathrm{T}$ found it difficult to adjust to sudden changes of routine and would show his reluctance to adapt by behaving immaturely and in a way unfitting to the new situation. One of the diagnostic criteria of ASD (DSM-V 2013:50) is '... excessive resistance to change...' Spratt et al. (2012:75) confirm that '... children with autism often show difficulties in adapting to change...'.

\section{Conclusion}

The results indicate that Learner T experienced EF challenges. He experienced a lack of response inhibition, which resulted in the inability to resist the urge to say something or comment out of turn. This meant that he did not take the time to evaluate a situation on how his behaviour may impact others. A lack of emotional control to manage his feelings, such as anxiety, frustration and disappointments, caused him to lash out in a socially and emotionally unacceptable manner. He experienced goal-directed persistence and sustained attention, and competing interests distracted him from working and persevering in completing a goal or task. By finding it difficult to adjust to sudden changes made him act out in a way that would be unfitting to the situation he found himself in. This may be the result of his experiencing a lack of flexibility of thinking.

Without acquiring and implementing appropriate EF skills, Learner $\mathrm{T}$ found it difficult to exhibit appropriate social behaviour in the inclusive learning environment. Greenstone (2011:101) confirms that 'EF skills are critical for both school and personal success, but have been traditionally underaddressed in academic settings'. She stresses that despite increased effort in recent years towards zero tolerance for aggression, oppositional behaviour and bullying, these behaviours persist in classroom environments. She stated that good EF skills are required so that pedagogical strategies can address not only what to learn in the classroom but also how to learn in the classroom.

For an ASD learner, who experiences EF skills, to be able to manage in inclusive education classrooms, a few recommendations are suggested. When an ASD learner is enrolled in an inclusive education environment, the teachers need to have access to support resources and literature to assist them with interventions and skills training. The ASD learner needs teachers who understand his or her disability and know how to offer appropriate support. Teachers need to be made aware of ASD characteristic traits and to offer a support system when needed. They need to be made aware that despite the communication and social challenges associated with ASD, many will achieve positive outcomes in areas that are not dependent on social interaction. These may be in the fields of mathematics, sciences and computers.

As a learner on the autism spectrum may present some unusual and challenging behaviours, and does not always respond to the usual methods of discipline, a collaborative 
support system needs to be put in place. This collaborative problem-solving process includes the support and assistance of parents or guardians, teachers, class assistant, special needs educator and health professionals.

Several studies and investigations have been conducted concerning creating a positive inclusive environment for learners with special needs (Ainscow 2005; Markussen 2004; Pijl \& Frostad 2010; Schwab et al. 2014). These studies were deemed necessary as it has been found that students with special needs have fewer interactions with peers, have more interaction with the teacher and are less accepted than their peers without special needs (Koster et al. 2010).

\section{Limitations and recommendations for future research}

This study has some limitations that may be considered for future research. Although this study was an in-depth case study investigation of one learner with ASD in a Grade 3 school environment, it focused only on one criterion describing ASD: Criterion A - social communication and societal integration. A larger and more comprehensive study involving Criterion B - restricted pattern of behaviour, interest or activities and hyper- or hypo-reactivity to sensory input - may yield additional interesting results (DSM-V 2013).

Another limitation is that, even though an in-depth case study approach allowed for a rich description, the study only focused on the chosen five behavioural domains of EF. A similar but more comprehensive study having included the domains of EF that incorporate the cognition skills associated with EF may extend the findings of this research.

A final limitation of the study is that only Teacher SM was interviewed. As the importance of a support system is mentioned in the conclusion, conducting interviews with the parents and health professionals involved with assisting the learner with ASD is a recommendation.

Given the importance of young children's development of appropriate EF skills in early childhood education, especially for a learner with special educational needs, it is recommended to take note of the following. The policymakers of early education policies that put great emphasis on emergent literacy and emergent numeracy skills are missing an important opportunity to increase their effectiveness by including attention to the development of executive functioning skills. The healthy development of EF must be supported with specialised practice and training programmes for special needs educators as well as educators who teach in an inclusive school environment. Diamond (2013:22) states: 'It's extremely important to help young children have good executive functioning because EFs early in life have been found to predict lifelong achievement, health, wealth, and quality of life'.

\section{Acknowledgements Competing interests}

The authors declare that they have no financial or personal relationships which may have inappropriately influenced them in writing this article.

\section{Authors' contributions}

P.d.J. was responsible for the research and writing of the manuscript. J.C. supervised, gave guidance and support, and edited the manuscript for final approval before submission.

\section{References}

Ainscow, M., 2005, 'Developing inclusive education systems: What are the levers for change?', Journal of Educational Change 6, 109-124. https://doi.org/10.1007/ s10833-005-1298-4

American Association on Intellectual and Developmental Disabilities (AAIDD), 2013 Diagnostic adaptive behaviour scale, American Psychiatric Association, Washington, DC.

American Psychiatric Association (APA), 2013, Diagnostic and statistical manual of mental disorders: DSM-5, American Psychiatric Association, Washington, DC.

Attwood, T., 2007, The complete guide to Asperger's syndrome, Jessica Kingsley Publishers, London.

Best, J.R. \& Miller, P.H., 2010, 'A developmental perspective on executive function', Child Development 81, 1641-1660. https://doi.org/10.1111/j.1467-8624.2010. 01499.x

Birtwell, K.B., Willoughby, B. \& Nowinski, L., 2016, 'Social, cognitive, and behavioural development of children and adolescents with autism spectrum disorder', in C.J. McDougal (ed.), Autism spectrum disorder, pp. 19-30, Oxford University Press, New York.

Cannon, L., Kenworthy, L., Alexander, C., Werner, M.A. \& Anthony, L.G., 2011, Unstuck and on target! Brookes Publishing, Baltimore, MD.

Centre on Development Child at Harvard University, 2011, Building the brains' 'Air Traffic Control' system: How early experiences shape the development of executive function: Working paper no 11, viewed 22 January 2016, from http://www. developingchild.harvard.edu

Cohen, L., Manion, L. \& Morrison, K., 2008, Research methods in education, 6th edn., Routledge, Abingdon.

Davide-Rivera, J., 2015, Why is it difficult for those with autism to complete tasks or meet goals? Understanding autism from the inside, Autism Answers, viewed 10 October 2015, from http://aspiewriter.com/2015/08/why-is-it-difficult-for-thosewith-autism-to-complete-tasks-or-meet-goals.html

Dawson, P. \& Guare, R., 2009, Smart but scattered, The Guilford Press, New York.

Dawson, P. \& Guare, R., 2010, Executive skills in children and adolescents: A practical guide to assessment and intervention, 2nd edn., Guilford Press, New York.

Dawson, P. \& Gaure, R., 2012, Coaching students with executive skills deficits, The Guilford Press, New York.

De Jager, P. \& Condy, J., 2011, 'The identification of sensory processing difficulties of learners experiencing Asperger's Syndrome (AS) in two mainstream Grade R classes', South African Journal of Childhood Education 1(2), 1-16. https://doi. classes, , South African Journo

De Luca, C.R. \& Leventer, R.J., 2008, 'Developmental trajectories of executive functions across the lifespan', in P. Anderson, V. Anderson \& R. Jacobs (eds.), Executive functions and the frontal lobes: A lifespan perspective, pp. 3-21, Taylor \& Francis, Washington, DC

Diamond, A., 2013, 'Executive functions', Annual Review of Psychology 64, 135-168. https://doi.org/10.1146/annurev-psych-113011-143750

Donohue, D. \& Bornman, J., 2014, 'The challenges of realising inclusive education in South Africa', South African Journal of Education 34(2), 1-14. https://doi. org/10.15700/201412071114

Elliot, P., 2013, Five fun activities for developing kids flexibility thinking skills, LearningWorks for kids, Inc., viewed 2 April 2016, from http://learningworksforkids. com/2013/12/5-fun-activities-for-developing-kids-flexibility-skills/

Engelbrecht, P., Oswald, M., Swart, E. \& Eloff, I., 2003, 'Including students with intellectual disabilities: Stressful for teachers?', International Journal of Disability,
Development and Education 50(3), 293-308. https://doi.org/10.1080/ Development and Educd

Gill, M.J., 2014, 'The possibilities of phenomenology for organizational research', Organizational Research Methods 17(2), 118-137. https://doi.org/10.1177/ 1094428113518348

Greenstone, H., 2011, 'Executive function in the classroom: Neurological implications for classroom intervention', LEARNing Landscapes 5(1), 101-113.

Gross, J.J. (ed.), 2007, Handbook of emotional regulation, Guilford Press, New York.

Guare, R., Dawson, P. \& Gaure, C., 2013, Smart but scattered teens, The Guilford Press, New York. 
Henning, E., Van Rensburg, W. \& Smit, B., 2007, Finding you own way in qualitative research, Van Schaik, Pretoria.

Herbert, M. \& Weintraub, K., 2012, The autism revolution: Whole-body strategies for making life all it can be, Ballantine Books, New York.

Herold, 2013. Autism spectrum disorder, The American Psychiatric Association viewed 2 November 2015, from http://www.dsm5.org/Documents/Autism\%20 Spectrum $\% 20$ Disorder $\% 2$ FFact $\% 20$ Sheet.pdf

Hill, H.L., 2004, 'Evaluating the theory of executive dysfunction in autism', Developmental Review 24, 189-233. https://doi.org/10.1016/j.dr.2004.01.001

Hughes, C. \& Graham, A., 2002, 'Measuring executive functions in childhood: Problems and solutions?', Child and Adolescent Mental Health 7, 131-142. https://doi.org/10.1111/1475-3588.00024

Isaac, 2015, 3 Tips for recording research interviews, Academic Transcription Services, viewed 3 February 2016, from https://www.academic-transcription-services. com/3-tips-for-recording-research-interviews/

Kana, R.K., Keller, T.A., Minshew, N.J. \& Just, M.A., 2007, 'Inhibitory control in highfunctioning autism: Decreased activation and under connectivity in inhibition networks', Biological Psychiatry 62, 198-206. https://doi.org/10.1016/j.biopsych. 2006.08.004

Kashdan, T.B. \& Rottenberg, J., 2010, 'Psychological flexibility as a fundamental aspect of health', Clinical Psychology Review 30(7), 865-878. https://doi.org/10.1016/j. cpr.2010.03.001

Knott, F. \& Dunlop A., 2007, Developing social interaction and understanding Newnorth Print for the National Autistic Society, London.

Koster, M., Pijl, S.J., Nakken, H. \& Van Houten, E., 2010, 'Social participation of students with special needs in regular primary education in the Netherlands', International Journal of Disability, Development and Education 57(1), 59-75. https://doi.org/10.1080/10349120903537905

Locke, R.L., Davidson, R.J., Kalin, N.H. \& Goldsmith, H.H., 2009, 'Children's contextinappropriate anger and salivary cortisol', Development Psychology 45(5), 1284-1297. https://doi.org/10.1037/a0015975

Malenka, R.C., Nestler, E.J. \& Hyman, S.E., 2009, 'Widely projecting systems: Monoamines, acetylcholine, and orexin', in A. Sydor \& R.Y. Brown, Molecular neuropharmacology: A foundation for clinical neuroscience, 2nd edn., Molecular neuropharmacology: A foundation for
pp. 155-157, McGraw-Hill Medical, New York.

Markussen, E., 2004, 'Special education: Does it help? A study of special education in Norwegian upper secondary schools', European Journal of Special Needs Education 19, 33-48. https://doi.org/10.1080/0885625032000167133

Miyake, A. \& Friedman, N.P., 2012, 'The nature and organization of individual differences in executive functions: Four general conclusions', Current Directions in Psychological Science 21(1), 8-14. https://doi.org/10.1177/0963721411429458

Nichols, L., 2011, Nomothetic vs. idiographic, viewed 3 February 2016, from https:// louisenichols.wordpress.com/2011/09/30/nomothetic-research-vs-idiographicresearch/

Pietkiewiz, I. \& Smith, J.A., 2014, 'A practical guide to using Interpretative Phenomenological Analysis in qualitative research psychology', Czasopismo Physchologiczne - Psychological Journal 20(1), 7-14.

Pijl, S.J. \& Frostad, P., 2010, 'Peer acceptance and self-concept of students with disabilities in regular education', European Journal of Special Needs Education 25(1), 93-105. https://doi.org/10.1080/08856250903450947
Richardson, T.H., 2008, 'Inhibitory control in psychiatric disorders: A review of neuropsychological and neuroimaging research', Undergraduate Research Journal for the Human Sciences 7, viewed 10 February 2016, from https://www.kon.org/ for the Human Sciences

Rule, P. \& John, V., 2011, Your guide to case study research, Van Schaik, Pretoria.

Samson, A.C., Hardan, A.Y., Podell, R.W., Phillips, J.M. \& Gross, J.J., 2014, 'Emotiona regulation in children and adolescents with autism spectrum disorder' International Society of Autism Research 8(1), 9-18. https://doi.org/10.1002/ aur.1387

Schwab, S., Gebhardt, M., Krammer, M., \& Gasteiger-Klicpera, B., 2014, 'Linking selfrated social inclusion to social behaviour. An empirical study of students with and without special education in secondary schools', European Journal of Specia Needs Education 30(1), 1-14.https://doi.org/10.1080/08856257.2014.933550

South Africa, Department of Basic Education, 2014, National strategy on screening, identification, assessment and support (SIAS), Government Printer, Pretoria.

South Africa, Department of Basic Education, 2015, Education statistics in South Africa 2013, Government Printer, Pretoria.

South Africa, National Department of Education, 2001, Education white paper 6: Special needs education. Building an inclusive education and training system, Government Printer, Pretoria.

South Africa, National Department of Education, 2002, Curriculum 2005. Assessment guidelines for inclusion, Government Printer, Pretoria.

South Africa, National Department of Education, 2008, National strategy on screening, identification, assessment and support (SIAS), Government Printer, Pretoria.

Spratt, E.G., Nicholas, J.S., Brady, K.T., Carpenter, L.A., Hatcher, C.R., Meekins, K.A. et al., 2012, 'Enhanced cortisol response to stress in children with autism', Journa of Autism and Developmental Disorders 42(1), 75-81. https://doi.org/10.1007/ s10803-011-1214-0

United Nations Children's Emergency Fund (UNICEF), 2012, Children with disabilities in South Africa: A situation analysis: 2001-2011, Department of Social Development/Department of Women, Children and People with Disabilities/ UNICEF, Pretoria.

Weiten, W., Dunn, D.S. \& Hammer, E.Y., 2011, Psychology applied to modern life: Adjustment in the 21st century, Wadsworth, Belmont, CA.

Wertz, S.R., 2012, Improving executive function in children with autism spectrum disorder, Growing Minds, Autism Programs, viewed 23 January 2016, from http:// www.autism-programs.com/articles-on-autism/improving-executive-function. htm

Yigal, A., Robert, M.J., Barton, J.S. \& Manoach, D.S., 2010, 'Reduced cognitive control of response inhibition by the anterior cingulate cortex in autism spectrum disorders', Neurolmage 52(1), 336-347. https://doi.org/10.1016/j.neuroimage. 2010.04.010

Yin, R.K., 2003, Case study research design and methods, 3rd edn., Sage, Thousand Oaks, CA

Ylvisaker, M., Hibbard, M. \& Feeney, T., 2006, What is initiation? Learnet, Camelo Media Group, New York, viewed 4 March 2016, from http://www.projectlearnet. org/tutorials/initiation.htm

Zohrabi, M., 2013, 'Mixed method research: Instruments, validity, reliability and reporting findings', Theory and Practice in Language Studies 3(2), 254-262. https://doi.org/10.4304/tpls.3.2.254-262 


\section{Appendix 1}

A copy of the observation sheet and interview questions used during data collection.

1. Observation example sheet

2. Interview question for Teacher SM

Observation sheet for Learner T (Example of multiple copies).

Day: ........ August.......September 2013.

\begin{tabular}{|c|c|c|c|c|}
\hline $\begin{array}{l}\text { Subjects: } \\
\text { Life skills, English Afrikaans, Maths, } \\
\text { Social Sciences and Natural Science } \\
\text { Physical Education, Art and drama, } \\
\text { and Computers }\end{array}$ & $\begin{array}{l}\text { Environmental Setting } \\
\text { Description } \\
\text { External factors }\end{array}$ & $\begin{array}{l}\text { Learner's response } \\
\text { Behavioural adaptation } \\
\text { challenge }\end{array}$ & $\begin{array}{l}\text { Teacher's immediate response } \\
\text { and intervention strategy }\end{array}$ & $\begin{array}{l}\text { EF challenges } \\
\text { Response Inhibition, Emotional control, } \\
\text { Task Initiation, Goal-directed } \\
\text { persistence and attention and Flexibility } \\
\text { of thinking }\end{array}$ \\
\hline $\begin{array}{l}\text { Subject: } \\
\text { Time: } \\
\text { Description: }\end{array}$ & $\begin{array}{l}\text { Venue: } \\
\text { Props: } \\
\text { New: }\end{array}$ & $\begin{array}{l}\text { Verbal: } \\
\text { Physical: } \\
\text { Second party/s: }\end{array}$ & $\begin{array}{l}\text { Class teacher: } \\
\text { Subject teacher: }\end{array}$ & $\begin{array}{l}\text { EF challenge: } \\
\text { Reason: }\end{array}$ \\
\hline
\end{tabular}

General comments:

\section{INTERVIEW QUESTIONS FOR TEACHER SM}

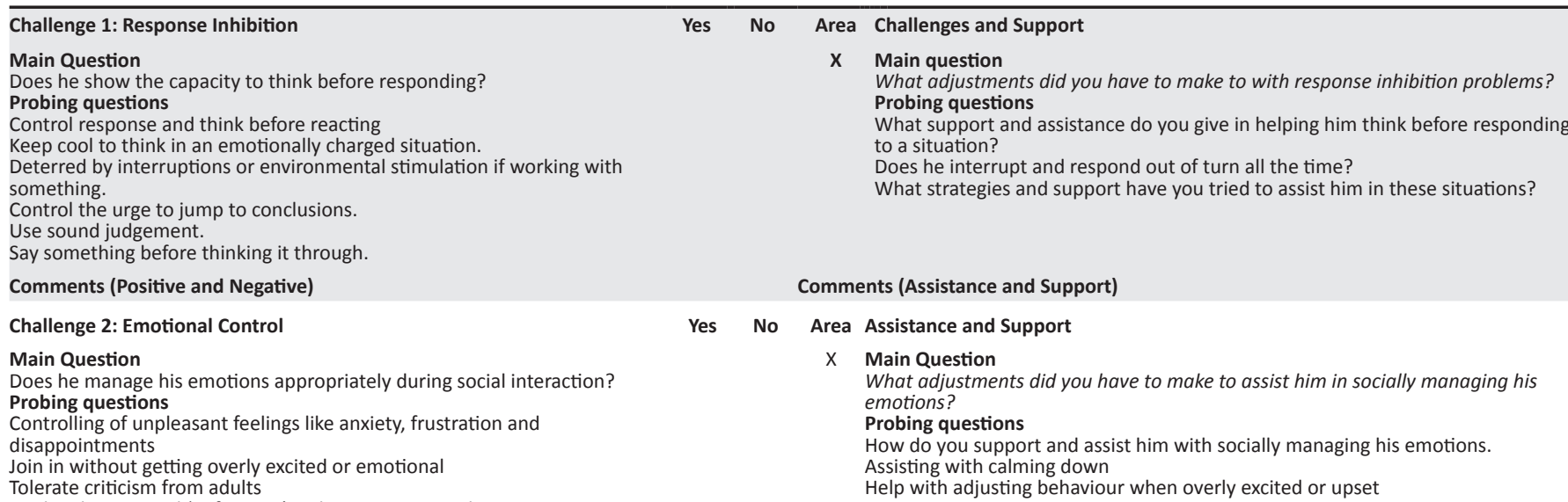

Tolerate criticism from adults

Adjust behaviour quickly after physical activity or stimulating situation

Comments (Positive and Negative)

Comments (Assistance and Support)

Challenge 3: Task Inhibition

Yes No Area Assistance and Support

Main Question

Can he start a project without undue procrastination?

Probing Questions

Does he start a task that is not popular now instead of later?

Can he follow through on instruction without too much delay?

Can he do daily tasks without being reminded?

Can he get right to work when instructions have been given?

\section{Comments (Positive and Negative)}

$X$ Main Question

What adjustments did you have to make to assist him in starting a given task or work?

Probing questions

Do you have to remind him constantly to start his work?

Do you have to support him by repeating the instructions individually again so that he can start his work?

Do you have to remind him daily of routine or daily procedures?

\section{Challenge 4: Goal-Directed Persistence}

Main Question

Can he follow through and complete a goal and not be put off by

distractions or competing interests?

Probing Questions

Does he persist even when finding it hard to achieve?

Does he refuse to start as it is not something he wants to do?

Does he do chores, and stick with it till completion?

Comments (Positive and Negative)

\section{Challenge 4: Sustained Attention}

Main Question

Can he keep paying attention to tasks in spite of being distracted?

Probing Questions

Paying attention despite feeling fatigued, bored or being distracted

Sustain attention for duration of task

Paying attention to relevant information

Flexible thinking - change 'train of thought'

Encode attention - remember when to use it later.

Comments (Assistance and Support)

Yes No Area Assistance and Support

$X \quad$ Main Question

What adjustments did you have to make to assist him in completing a set of goals or a task?

Probing Questions

Do you have to support and assist in helping him complete a set goal or task?

Do you constantly have to motivate him to complete chores or tasks given?

If not given support, does he complete a task on his own?

Comments (Assistance and Support)

Yes No Area Assistance and Support

X Main Question

What adjustments did you have to make to motivate him in paying attention? Probing questions

How do you assist in motivating him to pay attention?

Assisting in keeping him focussed

In helping him only focus on relevant information

Keeping motivated and interested in paying attention

Comments (Assistance and Support) 


\section{Challenge 6: Flexibility in Thinking}

\section{Main Question}

Can he adapt to change of conditions, obstacles, setbacks and new information and change?

Probing Questions

Does he adjust easily to unexpected change to routine?

Can he tolerate redirection from teacher when following of instructions?

Can he share his ideas and equipment without a fuss?

Can he deal with disappointments and manage frustration with minimum

fuss?

Comments (Positive and Negative)
Yes No

\section{Assistance and Support}

$X \quad$ Main Question

What adjustments did you have to make to assist and support him in change of routine or unexpected setbacks?

Probing Questions

Does he need assistance and support to help him with change in routine and

unexpected setbacks

Does he need constant support when there is a change in routine?

Does he need support to deal with disappointments and to manage his

frustration if things do not go according to plan?

Comments (Assistance and Support) 